\title{
Effect of admission glycated hemoglobin on short term outcome of acute ST elevation myocardial infarction in non-diabetic patient
}

\begin{abstract}
Background: Coronary artery disease is one of the most important causes of death in industrialized countries. Diabetes mellitus is a modifiable risk factor for coronary artery disease. It increases the risk of coronary artery disease by 2 to 4 -fold.This increased risk occurs in patients with DM and non-diabetic patients with impaired glucose tolerance (IGT). Moreover, increased admission glucose levels may increase mortality rates in patients with acute myocardial infarction (AMI), regardless of diabetic status.
\end{abstract}

Objective: To assess the relationship between admissions HbAlc level and short term outcomes of acute ST elevation myocardial infarction treated by primary PCI in nondiabetic patients

Material and Methods: This is an observational study was conducted at Coronary care unit \& coronary catheterization lab unit of cardiology department in Ain Shams University hospitals in the period from 1-9-2018 till 1-3-2019.

Results: 100 patients without prior diagnosis of DM were included in our study population Three categories of patients were created according to HbAlc level: Group $1(<5.7 \%)$ : 46 patients (46\%); Group 2 (5.7 to 6.4\%): 38 patients (38\%); Group 3 (>6.5\%): 16 patients $(16 \%)$. Baseline characteristics of the study population are shown in Table 1, the mean age of our sample was $55.06 \pm 11.73$ years and $96 \%$ were males, there was highly statistically significant difference found between the 3 groups regarding SYNTAX score with P-value $(0.002) \&$ another highly significant difference in EF between the 3 groups.

Conclusion: The present study showed that admission higher HbA1c level in nondiabetic patients presented by acute STEMI is associated with more severe CAD. MACE \& thrombus burden were not found in this study to be related to glycated hemoglobin. Introducing measurement of $\mathrm{HbAlc}$ in the $\mathrm{CCU}$ seems to be a simple method to obtain important information on the expected severity of coronary lesions.

Keywords: admission glycated hemoglobin, angiographic characteristics, myocardial infarction
Volume 12 Issue $6-2019$

\section{Youssef Bassily RA, Abdel Qawy EM, Mohamed Helmi HG, Ibrahim El Abd AA \\ Department of Cardiology, Ain Shams University, Egypt}

Correspondence: Ehab Elfekky, Department of Cardiology, Faculty of Medicine, Ain Shams University, Cairo, Egypt, Email ehablfekey76@yahoo.com

Received: September 10, 2019 | Published: December 16, 2019
Abbreviations: AMI, acute myocardial infarction; MI, myocardial infarction; HbA1c, hemoglobin $\mathrm{A} 1 \mathrm{C}$; $\mathrm{CIN}$, contrast induced nephropathy; MACE, major adverse cardiac events; NS, nonsignificant; HS, highly significant

\section{Introduction}

Coronary artery disease is one of the most important cause of death in industrialized countries. Diabetes mellitus is a modifiable risk factor for coronary artery disease. It increases the risk of coronary artery disease by 2 to 4 -fold.This increased risk occurs in patients with DM and nondiabetic patients with impaired glucose tolerance (IGT). Moreover, increased admission glucose levels may increase mortality rates in patients with acute myocardial infarction (AMI), regardless of diabetic status. Up till now there is no agreement about the threshold glycemic level for developing cardiovascular complications. ${ }^{1-10}$

Increased catecholamine levels in acute myocardial infarction (AMI) lead to stress induced hyperglycemia, so looking only at plasma glucose levels at the time of an AMI cannot predict the prognosis. ${ }^{11}$ Glycosylated hemoglobin $\mathrm{A} 1 \mathrm{C}(\mathrm{HbAlc})$ is a measure of the average blood glucose levels over 2 months ${ }^{12}$ and is minimally affected by acute hyperglycemia often observed in myocardial infarction (MI). Elevated HbAlc levels are associated with an increased risk for future micro-vascular and macrovascular disease..$^{13} \mathrm{HbAlc}$ can be assessed in the non-fasted state and has higher reproducibility than fasting glucose. ${ }^{14}$ There is consistent evidence that optimal glycemic control (defined as $\mathrm{HbAlc} \leq 7 \%$ ) results in a lower incidence of micro-vascular complications in both type 1 and type $2 \mathrm{DM} .^{15}$ Moreover, a report found that elevated $\mathrm{HbAlc}$ levels are also predictive for cardiovascular disease and mortality in patients without DM, independent of the fasting glucose value. ${ }^{16}$

Some data suggest a high HbAlc level as a marker of extensive coronary arterial disease. ${ }^{17}$ There are some other studies supporting the association between admission serum $\mathrm{HbAlc}$ level and increased longterm mortality of non-diabetic patients admitted with STEMI and a higher rate of CAD in these patients. ${ }^{18,19}$ There have been few studies which have shown $\mathrm{HbAlc}$ to be predictive of CAD in non-diabetes, but only in limited studies $\mathrm{HbA} 1 \mathrm{c}$ has been correlated with angiographically proven CAD using Syntax score which was developed as a comprehensive angiographic scoring tool for quantification of coronary lesions with respect to their number, location, and complexity. ${ }^{20,21}$

\section{Aim of the study}

The aim of the present study was to assess the effect of admission 
HbA1c on outcome of 1ry PCI and short-term outcome of adverse cardiac events in patients without known diabetes mellitus who were admitted with acute ST elevation myocardial infarction.

\section{Patients and methods}

a. Type of Study: Observational.

b. Study Setting: Coronary care unit \& coronary catheterization lab unit of cardiology department in Ain Shams University hospitals.

c. Study Period: 6 months (From 1-9-2018 till 1-3-2019).

d. Study Population.

\section{Inclusion criteria}

i. Chest pain with ECG criteria of STEMI.

ii. New onset left bundle branch block.

iii. Elevated levels of troponin according to the criteria established by current guidelines.

Study population includes patients who came to our hospitals \& were directly transported to the catheterization laboratory on arrival, and acute coronary angiography was performed with subsequent PCI when indicated as part of the routine treatment for all STEMI patients in our institute \& those who received thrombolysis in other hospitals $\&$ referred to us for further management.

Table I Demographic data of the study population

\begin{tabular}{lll}
\hline & & No. $=100$ \\
\hline Age & Mean \pm SD & $55.0 \pm 11.73$ \\
& Range & $30-88$ \\
Sex & Female & $4(4.0 \%)$ \\
& Male & $96(96.0 \%)$ \\
Smoking & Negative & $30(30.0 \%)$ \\
& Positive & $70(70.0 \%)$ \\
Hypertension & Negative & $76(76.0 \%)$ \\
& Positive & $24(24.0 \%)$ \\
Family History & Negative & $98(98.0 \%)$ \\
& Positive & $2(2.0 \%)$ \\
& Negative & $86(86.0 \%)$ \\
Drug History & Positive & $14(14.0 \%)$ \\
& Negative & $88(88.0 \%)$ \\
& Positive & $12(12.0 \%)$ \\
\hline
\end{tabular}

\section{Exclusion criteria}

i. Anemia.

ii. Acute inflammatory diseases.

iii. Hepatic failure.

iv. Autoimmune diseases. v. Cancer

vi. Patients with chronic renal failure in a hemodialysis program.

vii. Known DM.

viii. Previous CABG \& previous MI.

\section{Sample size}

100 patients who present to Ain Shams University \& Specialized hospitals during the study period will be enrolled in the study after fulfilling the inclusion criteria.

\section{Ethical considerations}

Ain Shams university ethical committee approval was obtained according to the ethical guidelines of the 1975 declaration of Helsinki as revised in 2008 .

Study tools: Checklist for assessment of all the clinical data relevant to the patient. All these sheets were collected then the data entry was carried out through a computer system in order to establish a databased system for all the patients.

\section{All patients after written informed consent were subjected to the following}

i. Proper history taking including clinical, demographic data, risk factors and co-morbidities, duration of hospital stay.

ii. Laboratory investigations especially glycated hemoglobin at admission.

iii. Transthoracic Echocardiography: Ejection fraction measured by 2D eye balling, ${ }^{22-30} \mathrm{LV}$ dimensions by M-mode, mitral regurgitation, or any other mechanical complications.

iv. Coronary Angiography: angiographic data will be recorded to all patients to calculate Syntax score. (The SYNTAX score has been developed to prospectively characterize the coronary vasculature with respect to the number of lesions and their functional impact, location, and complexity. Higher SYNTAX scores, indicative of more complex disease are hypothesized to represent a bigger therapeutic challenge and to have potentially worse prognosis). ${ }^{31}$

\section{Primary endpoints}

a. Correlation of $\mathrm{HbAlc}$ level with angiographic finding after primary PCI concerning TIMI flow, thrombus burden \& complexity of lesions assessed by SYNTAX score.

b. The correlation of $\mathrm{HbAlc}$ level with major adverse cardiac events (MACE) during hospital stay which includes CV mortality, malignant arrhythmia, cardiogenic shock, congestive heart failure $\&$ need for mechanical ventilation.

\section{Secondary endpoints}

Development of contrast induced nephropathy (CIN).

\section{Statistical analysis}

Data was collected, tabulated and all the results will be subjected to adequate statistical analysis using Chi-square test, One Way ANOVA test \& Kruskal Wallis test. P-value $>0.05$ : Non significant (NS); $\mathrm{P}$-value $<0.05$ : Significant (S); P-value $<0.01$ : highly significant (HS). 
Table 2 Comparison between the 3 groups regarding demographic data

\begin{tabular}{|c|c|c|c|c|c|c|c|}
\hline & & Normal group & Pre DM group & DM group & Tocs & D & Sim \\
\hline & & No. $=46$ & No. $=38$ & No. $=16$ & & & \\
\hline & Mean $\pm S D$ & $54.22 \pm 11.65$ & $57.79 \pm|2.8|$ & $51.00 \pm 7.61$ & & & \\
\hline Age & Range & $30-82$ & $31-88$ & $40-60$ & $2.134^{\circ}$ & 0.122 & NS \\
\hline Sex & Female & $4(8.7 \%)$ & $0(0.0 \%)$ & $0(0.0 \%)$ & & 0007 & \\
\hline sex & Male & $42(91.3 \%)$ & $38(100.0 \%)$ & $16(100.0 \%)$ & $4.071^{\circ}$ & 0.001 & INS \\
\hline oking & Negative & $12(26.1 \%)$ & $16(42.1 \%)$ & $2(12.5 \%)$ & $5320 *$ & 0.970 & NS \\
\hline काח & Positive & $34(73.9 \%)$ & $22(57.9 \%)$ & I4(87.5\%) & $3.32 U^{\circ}$ & 0.070 & No \\
\hline Hynertension & Negative & $32(69.6 \%)$ & $32(84.2 \%)$ & $12(75.0 \%)$ & $457 *$ & 0293 & NS \\
\hline (19) & Positive & $14(30.4 \%)$ & $6(15.8 \%)$ & $4(25.0 \%)$ & 2.431 & 0.270 & INS \\
\hline Family History & Negative & $46(100.0 \%)$ & $36(94.7 \%)$ & $16(100.0 \%)$ & $3330 *$ & 0189 & NS \\
\hline 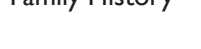 & Positive & $0(0.0 \%)$ & $2(5.3 \%)$ & $0(0.0 \%)$ & 3.550 & 0.107 & TNS \\
\hline Druo History & Negative & $36(78.3 \%)$ & $36(94.7 \%)$ & I4(87.5\%) & 472 & 0094 & \\
\hline 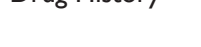 & Positive & $10(21.7 \%)$ & $2(5.3 \%)$ & $2(12.5 \%)$ & 1.128 & ד. & No \\
\hline & Negative & $40(87.0 \%)$ & $32(84.2 \%)$ & $16(100.0 \%)$ & 74 & 0253 & \\
\hline 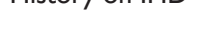 & Positive & $6(13.0 \%)$ & $6(15.8 \%)$ & $0(0.0 \%)$ & 2.040 & (2) & T \\
\hline
\end{tabular}

P-value $>0.05$ : Non significant (NS); P-value <0.05: Significant(S); $\mathrm{P}$-value $<0.0 \mathrm{I}$ : highly significant(HS)

*:Chi-square test; $\bullet:$ One Way ANOVA test; $\ddagger$ : Kruskal Wallis test

Table 3 Comparison between DM groups regarding admission HBA Ic, pain to first medical contact(FMC), and type of STEMI

\begin{tabular}{|c|c|c|c|c|c|c|c|}
\hline & & \multirow{2}{*}{$\begin{array}{l}\text { Normal group } \\
\text { No. }=46\end{array}$} & \multirow{2}{*}{$\begin{array}{l}\text { Pre DM group } \\
\text { No. }=\mathbf{3 8}\end{array}$} & \multirow{2}{*}{$\begin{array}{l}\text { DM group } \\
\text { No. }=16\end{array}$} & \multirow{2}{*}{-Test value } & \multirow{2}{*}{ P-value } & \multirow{2}{*}{ Sig. } \\
\hline & & & & & & & \\
\hline \multirow{2}{*}{ HBAIC } & Mean $\pm S D$ & $5.33 \pm 0.25$ & $5.97 \pm 0.19$ & $7.84 \pm 1.59$ & \multirow{2}{*}{$85.720 •$} & \multirow{2}{*}{0.000} & \multirow{2}{*}{ HS } \\
\hline & Range & 4.8- 5.6 & $5.7-6.4$ & $6.5-11.6$ & & & \\
\hline \multirow{2}{*}{ Pain to FMC } & Median(IQR) & $8(4-12)$ & $6(4-11)$ & $4(2.5-9.5)$ & \multirow{2}{*}{$4.117 \neq$} & \multirow{2}{*}{0.128} & \multirow{2}{*}{ NS } \\
\hline & Range & $2-24$ & I -24 & $1-12$ & & & \\
\hline \multirow{6}{*}{ Type of STEMI } & Anterior & $32(69.6 \%)$ & $18(47.4 \%)$ & $6(37.5 \%)$ & \multirow{6}{*}{22.156} & \multirow{6}{*}{0.014} & \multirow{6}{*}{ S } \\
\hline & Lateral & $2(4.3 \%)$ & $2(5.3 \%)$ & $0(0.0 \%)$ & & & \\
\hline & Inferior & $8(17.4 \%)$ & $8(21.1 \%)$ & $6(37.5 \%)$ & & & \\
\hline & Infroposterior & $2(4.3 \%)$ & $8(21.1 \%)$ & $2(12.5 \%)$ & & & \\
\hline & Infrolateral & $0(0.0 \%)$ & $0(0.0 \%)$ & $2(12.5 \%)$ & & & \\
\hline & Antroseptal & $2(4.3 \%)$ & $2(5.3 \%)$ & $0(0.0 \%)$ & & & \\
\hline
\end{tabular}

P-value >0.05: Non significant(NS); P-value <0.05: Significant(S); P-value< 0.0 I: highly significant(HS)

$*:$ Chi-square test; $\bullet:$ One Way ANOVA test; $\ddagger:$ Kruskal Wallis test

Table 4 Comparison between different DM groups regarding SYNTAX score \& EF by 2-D eye - balling

\begin{tabular}{|c|c|c|c|c|c|c|c|}
\hline & & Normal group & Pre DM group & DM group & & & \\
\hline & & No. $=46$ & No. $=38$ & No. $=16$ & & P-value & Sig. \\
\hline SYNTAX & Mean $\pm S D$ & $14.96 \pm 5.07$ & $16.74 \pm 8.19$ & $19.94 \pm 4.35$ & $6.458 \bullet$ & 0.002 & $\mathrm{HS}$ \\
\hline EF & Mean $\pm S D$ & $38.78 \pm 9.96$ & $45.79 \pm 11.01$ & $45.63 \pm 10.22$ & $5.551 \bullet$ & 0.005 & HS \\
\hline
\end{tabular}

P-value >0.05: Non significant(NS); P-value <0.05: Significant(S); P-value< 0.0 I: highly significant(HS)

*:Chi-square test; $\bullet$ : One Way ANOVA test; $\ddagger$ Kruskal Wallis test

Citation: Youssef BRA, Abdel QEM, Mohamed HHG, et al. Effect of admission glycated hemoglobin on short term outcome of acute ST elevation myocardial infarction in non-diabetic patient. J Cardiol Curr Res. 2019; I 2(6):I65-I70. DOI: I0.I5406/jccr.2019.12.0046 I 
Table 5 Comparison between the 3 groups regarding Thrombus burden, TIMI flow

\begin{tabular}{|c|c|c|c|c|c|c|c|c|c|}
\hline & \multicolumn{2}{|c|}{ Normal group } & \multicolumn{2}{|c|}{ Pre DM group } & \multicolumn{2}{|c|}{ DM group } & \multirow{2}{*}{ Test value* } & \multirow{2}{*}{ P-value } & \multirow{2}{*}{ Sig. } \\
\hline & No. & $\%$ & No. & $\%$ & No. & $\%$ & & & \\
\hline \multirow{2}{*}{ Thrombus burden } & 032 & $69.6 \%$ & 24 & $63.2 \%$ & 6 & $37.5 \%$ & \multirow{2}{*}{5.215} & \multirow{2}{*}{0.074} & \multirow{2}{*}{ NS } \\
\hline & 114 & $30.4 \%$ & 14 & $36.8 \%$ & 10 & $62.5 \%$ & & & \\
\hline \multirow{4}{*}{ TIMI flow } & 02 & $4.3 \%$ & 0 & $0.0 \%$ & 0 & $0.0 \%$ & \multirow{4}{*}{13.346} & \multirow{4}{*}{0.038} & \multirow{4}{*}{$S$} \\
\hline & 10 & $0.0 \%$ & 0 & $0.0 \%$ & 2 & $12.5 \%$ & & & \\
\hline & 216 & $34.8 \%$ & 14 & $36.8 \%$ & 4 & $25.0 \%$ & & & \\
\hline & 328 & $60.9 \%$ & 24 & $63.2 \%$ & 10 & $62.5 \%$ & & & \\
\hline
\end{tabular}

P-value >0.05: Non significant(NS); P-value <0.05: Significant(S); P-value< 0.0I: highly significant(HS)

*:Chi-square test; $\bullet:$ One Way ANOVA test; $\ddagger:$ Kruskal Wallis test

Table 6 Comparison between the 3 groups regarding MACE \& CIN

\begin{tabular}{|c|c|c|c|c|c|c|c|c|c|c|}
\hline & & \multicolumn{2}{|c|}{ Normal group } & \multicolumn{2}{|c|}{ Pre DM group } & \multicolumn{2}{|c|}{ DM group } & \multirow{2}{*}{-Test value* } & \multirow{2}{*}{ P-value } & \multirow{2}{*}{ Sig. } \\
\hline & & No. & $\%$ & No. & $\%$ & No. & $\%$ & & & \\
\hline \multirow{2}{*}{ MACE } & Negative & 40 & $87.0 \%$ & 34 & $89.5 \%$ & 14 & $87.5 \%$ & \multirow{2}{*}{0.129} & \multirow{2}{*}{0.937} & \multirow{2}{*}{ NS } \\
\hline & Positive & 6 & $13.0 \%$ & 4 & $10.5 \%$ & 2 & $12.5 \%$ & & & \\
\hline \multirow{2}{*}{$\mathrm{CIN}$} & Negative & 42 & $91.3 \%$ & 32 & $84.2 \%$ & 14 & $87.5 \%$ & \multirow{2}{*}{0.996} & \multirow{2}{*}{0.608} & \multirow{2}{*}{ NS } \\
\hline & Positive & 4 & $8.7 \%$ & 6 & $15.8 \%$ & 2 & $12.5 \%$ & & & \\
\hline
\end{tabular}

P-value >0.05: Non significant(NS); P-value <0.05: Significant(S); P-value< 0.0 I: highly significant(HS)

*:Chi-square test

Table 7 Correlation between $\mathrm{HB}_{\text {AIC }}$ with Age, Pain to FMC, SYNTAX, and EF

\begin{tabular}{lll}
\hline & \multicolumn{2}{l}{ HBAIC } \\
\cline { 2 - 3 } & $\mathbf{R}$ & P-value \\
\hline Age & 0.022 & 0.829 \\
Pain to FMC & $-0.200^{*}$ & 0.046 \\
SYNTAX & $0.492^{* *}$ & 0.000 \\
EF & 0.125 & 0.215 \\
\hline
\end{tabular}

\section{Results}

The Previous table shows that there was no statistically significant difference found between DM groups regarding Demographic data. The Previous table shows that there was highly statistically significant difference found between the 3 groups regarding HBA1C with $\mathrm{P}$-value $(0.000)$ while there was no statistically significant difference found between DM groups regarding pain to FMC. The Previous table shows that there was highly statistically significant difference found between the 3 groups regarding SYNTAX score with P-value (0.002) $\&$ another highly significant difference in EF between the 3 groups. In the previous table, there was no statistically significant difference found between the 3 groups regarding Thrombus burden.

The same table shows another statistically significant difference found between the 3 groups regarding TIMI flow with P-value (0.038) being higher in pre-DM group with $63.2 \%$ of the pre DM had a better TIMI flow. This table shows no statistically significant difference found between the 3 groups regarding MACE \& CIN. The Previous table shows that there was highly statistically significant correlation between level of $\mathrm{Hb}_{\mathrm{Alc}}$ on admission \& SYNTAX score with p- value $(0.000)$ while there was no statistically significant correlation found between groups regarding $\mathrm{EF}$.

\section{Discussion}

Stress hyperglycemia commonly occurs in acute myocardial infraction (AMI) secondary to increased catecholamine levels, so looking only at plasma glucose levels at the time of an AMI cannot predict the prognosis. ${ }^{12}$ Glycosylated hemoglobin A1c (HbAlc) is a measure of the average blood glucose levels over 2 months ${ }^{22}$ and is minimally affected by acute hyperglycemia often observed in myocardial infarction (MI). Using the glucose test, we may fail to identify the undiagnosed DM due to high prevalence of stress hyperglycemia in this population. HbAlc reflects long-term glycometabolic control, ${ }^{24}$ and its level as higher than $6.5 \%$ is now considered as an alternative category of DM. While according to a recent guideline for $\mathrm{DM}$ diagnosis, $\mathrm{HbA} 1 \mathrm{c}$ from $5.7 \%$ to $6.5 \%$ is considered as pre-diabetes. ${ }^{25}$ In our study, patients with underlying prediabetes and unknown overt DM after hospital admission represent a major portion from the study population (38\% for the pre-diabetes $\& 16 \%$ for newly diagnosed cases). It is reported that $25 \%$ of AMI patients had newly diagnosed DM. In our study, 16 newly diagnosed cases of diabetes $(16 \%)$ were documented..$^{23}$

We found a substantial proportion of patients suffering from AMI with underlying pre-diabetes and unknown overt DM after hospital admission. These patients with disturbed glucose metabolism had worse early outcomes, characterized by progressive increased rates of in-hospital mortality according to HbAlc \& higher SYNTAX score 
indicating more complex lesions in angiography. Our results showed a highly statistically significant difference concerning the SNTAX score was noted between the 3 groups: in the normal group SYNTAX ranged from 6-22 with Mean \pm SD 14.96 \pm 5.07 , while it was 3-34 (Mean \pm SD 16.74 \pm 8.19 ) in group 2, finally for the DM group (10-28.5 Mean \pm SD 19.94 \pm 4.35$)$.

This was concordant with previous studies by Cakmak et al. ${ }^{26}$ and Kassaian et al. ${ }^{27}$ This can be explained by insulin resistance in hyperglycemia promoting molecular mechanism by Advanced Glycation End Products (AGEs) which are intimately involved in the pathophysiology of cardiovascular disease by stimulating inflammation, contributing to atheroma formation modulating vascular stiffness and the disturbed endothelial function by reduction of nitric oxide release and increased vascular smooth muscle proliferation ${ }^{[28]}$ and increase of $\mathrm{HbA} 1 \mathrm{c}$ one percent is associated with 2.8-fold increase in $\mathrm{CAD}$.

In our study, we found that most of the patients having normal $\mathrm{HbA1c}$ had lower LVEF (mean 38.78 \pm 9.96 ) as compared to most of the patients with high normal HbAlc, who had higher LVEF $(45.79 \pm 11.01)$ This is discordant with Razzaq et al. ${ }^{29}$ showed that the mean EF was significantly lower in group $\mathrm{HbA} 1 \mathrm{c} 6.5-8.5$ and in group $\mathrm{HbA} 1 \mathrm{c}>8.5$ as compared with that group $<6.5$. A linear decrease in EF was found with rising $\mathrm{HbA} 1 \mathrm{c}$ levels in patients with unstable angina $(\mathrm{P}=0.0043)$, with ST-segment elevation myocardial infarction $(\mathrm{P}=$ $0.0290)$ and non-segment elevation myocardial infarction $(\mathrm{P}=0.0015)$.

In our study, TIMI flow was found unexpectedly higher in group 2 (Pre-diabetics) with statistically significance as P-value was $(0.038)$ showing $63.2 \%$ of the pre DM had TIMI flow III. This finding was not in agreement with Planner et al. who explained the fact that hyperglycemia is associated with higher rate of TIMI $0 \backslash 1$ and lower rate of complete revascularization TIMI and hyperglycemia adversely affect platelets function and endothelial function, promote inflammation, and result in pro-coagulable condition; it is worth mentioning that hyperglycemia per se in STEMI leads to impaired coronary flow on presentation and after primary PCI. ${ }^{32}$ The result of MI, however, was still less conclusive as in-hospital managements, such as intervention procedures and medications, may influence the clinical outcomes.

\section{Conclusion}

The present study showed that admission higher HbAlc level in non-diabetic patients presented by acute STEMI is associated with more severe CAD. MACE \& thrombus burden were not found in this study to be related to glycated hemoglobin. Introducing measurement of HbAlc in the CCU seems to be a simple method to obtain important information on the expected severity of coronary lesions.

\section{Recommendations}

The sample size of the study was small mostly due to unaffordability of patients. A larger sample size would have yielded better outlook towards the association of $\mathrm{HbAlc}$ with prognosis of patients with acute coronary syndrome.

\section{Acknowledgments}

None.

\section{Conflicts of interest}

Author declares that tier is no conflicts of interest towards the article.

\section{Refernces}

1. Park K. Park's textbook of preventive and social medicine. Preventive Medicine in Obstet, Paediatrics and Geriatrics. India: Bhanot Publishers; 2015. p. 339.

2. Garcia MJ, McNamara PM, Gordon T, et al. Morbidity and mortality in diabetes in the Framingham population. Diabetes. 1974;23(2):105-116.

3. Timmer JR, van der Horst IC, Ottervanger JP, et al. Prognostic value of admission glucose in non-diabetic patients with myocardial infarction. Am Heart J. 2004;148(3):399-404.

4. Wiviott SD, Braunwald E, Angiolillo DJ, et al. Greater clinical benefit of more intensive oral antiplatelet therapy with prasugrel in patients with diabetes mellitus in the trial to assess improvement in therapeutic outcomes by optimizing platelet inhibition with prasugrel-Thrombolysis in Myocardial Infarction 38. Circulation. 2008;118(16):1626-1636.

5. Gerstein HC, Yusuf S. Dysglycaemia and risk of cardiovascular disease. Lancet. 1996;347:949-950.

6. Fava S, Aquilina O, Azzopardi J, et al. The prognostic value of blood glucose in diabetic patients with acute myocardial infarction. Diabet Med. 1996;13(1):80-83.

7. Oswald GA, Smith CC, Betteridge DJ, et al. Determinants and importance of stress hyperglycaemia in non-diabetic patients with myocardial infarction. Br Med J (Clin Res Ed). 1986;293(6552):917-922.

8. Diabetes Control and Complications Trial. The absence of a glycemic threshold for the development of long-term complications: the perspective of the Diabetes Control and Complications Trial. Diabetes. 1996;45(10):1289-1298.

9. Balkau B, Bertrais S, Ducimetiere P, et al. Is there a glycemic threshold for mortality risk? Diabetes Care. 1999;22(5):696-699.

10. Shaw JE, Zimmet PZ, Hodge AM, et al. Impaired fasting glucose: how low should it go?. Diabetes Care. 2000;23(1):34-39.

11. Koraćević G, Petrović S, Tomašević M, et al. Stress hyperglycemia in acute myocardial infarction. Facta universitatis-series: Medicine and Biology. 2006;13(3):152-157.

12. Gabbay KH, Hasty K, Breslow JL, et al. Glycosylated hemoglobins and long-term blood glucose control in diabetes mellitus. J Clin Endocrinol Metab. 1977;44(5):859-864.

13. Malmberg K, Rydén L, Wedel H, et al. Intense metabolic control by means of insulin in patients with diabetes mellitus and acute myocardial infarction (DIGAMI 2): effects on mortality and morbidity. Eur Heart J. $2005 ; 26(7): 650-661$

14. American Diabetes Association. Standards of medical care in diabetes-2009. Diabetes Care. 2009;1:13-61.

15. Stamler J, Vaccaro O, Neaton JD, et al. Diabetes, other risk factors, and 12-yr cardiovascular mortality for men screened in the Multiple Risk Factor Intervention Trial. Diabetes Care. 1993;16(2):434-444.

16. Selvin E, Steffes MW, Zhu H, et al. Glycated hemoglobin, diabetes, and cardiovascular risk in nondiabetic adults. New England Journal of Medicine. 2010;362(9):800-811.

17. Khaw KT, Wareham N. Glycated hemoglobin as a marker of cardiovascular risk. Curr Opin Lipidol. 2006;17(6):637-643. 
18. Timmer JR, Hoekstra M, Nijsten MW, et al. Prognostic value of admission glycosylated hemoglobin and glucose in nondiabetic patients with STsegment-elevation myocardial infarction treated with percutaneous coronary intervention. Circulation. 2011;124(6)110-124.

19. Pai JK, Cahill LE, Hu FB, et al. Hemoglobin a1c is associated with increased risk of incident coronary heart disease among apparently healthy, nondiabetic men and women. J Am Heart Assoc. 2013;2(2): $\mathrm{e} 000077$.

20. Sianos G, Morel MA, Kappetein AP, et al. The SYNTAX Score: an angiographic tool grading the complexity of coronary artery disease. EuroIntervention. 2005; 1(2): 219-227.

21. Choudhary S. Association of syntax score with short-term outcomes among acute ST-elevation myocardial infarction patients undergoing primary PCI. Indian Heart J. 2016;149-154.

22. Naito R, Miyauchi K, Ogita M, et al. Impact of admission glycemia and glycosylated hemoglobin A1c on long-term clinical outcomes of non-diabetic patients with acute coronary syndrome. J Cardiol. 2014;63(2):106-611.

23. Norhammar A, Tenerz $\AA$, Nilsson G, et al. Glucose metabolism in patients with acute myocardial infarction and no previous diagnosis of diabetes mellitus: a prospective study. The Lancet. 2012;359(9324): 2140-2144.

24. Nathan DM, Turgeon H, Regan S. Relationship between glycated haemoglobin levels and mean glucose levels over time. Diabetologia. 50(11):2239-2244.
25. Association AD. Diagnosis and classification of diabetes mellitus. Diabetes Care. 2010;33(1):S62-S69.

26. Cakmak M, Cakmak N, Cetemen S, et al. The value of admission glycosylated hemoglobin level in patients with acute myocardial infarction. Can J Cardiol. 2008;24(5):375-378.

27. Kassaian SE, Goodarzynejad H, Boroumand MA, et al. Glycosylated hemoglobin $(\mathrm{HbA} 1 \mathrm{c})$ levels and clinical outcomes in diabetic patients following coronary artery stenting. Cardiovasc Diabetol. 2012;11(1): 82.

28. Prasad A, Bekker P, Tsimikas S. Advanced glycation end products and diabetic cardiovascular disease. Cardiol Rev. 2012;20(4):177-183.

29. Razzaq MK, Rasheed JI, Mohmmad HS. The value of admission glucose and glycosylated hemoglobin in patients with acute coronary syndrome. Iraqi Postgrad Med J. 2013;12.

30. Quiñones MA, Waggoner AD, Reduto LA, et al. A new, simplified and accurate method for determining ejection fraction with two-dimensional echocardiography. Circulation. 1981;64(4):744-753.

31. Sianos G, Morel MA, Kappetein AP, et al. The SYNTAX Score: an angiographic tool grading the complexity of coronary artery disease. EuroIntervention. 2005;1(2):219-227.

32. Planer D, Witzenbichler B, Guagliumi G, et al. Impact of hyperglycemia in patients with ST-segment elevation myocardial infarction undergoing percutaneous coronary intervention: the HORIZONS-AMI trial. Int $J$ Cardiol. 2013;10;167(6):2572-2579. 